\title{
THE REMARKABLE BROAD ABSORPTION LINE QSO 0059-2735 WITH EXTENSIVE Fe II ABSORPTION
}

\author{
C. HAZARD \\ Department of Physics and Astronomy, University of Pittsburgh \\ RICHARD G. MCMAHON \\ Institute of Astronomy, University of Cambridge \\ JOHN K. WEBB \\ Sterrewacht, Leiden \\ AND \\ Donald C. Morton \\ Herzberg Institute of Astrophysics, National Research Council, Canada \\ Received 1987 March 17; accepted 1987 May 15
}

\begin{abstract}
We describe the discovery and preliminary spectroscopy of the broad absorption line (BAL) QSO $0059-2735\left(z_{\mathrm{em}}=1.595\right)$ which shows features never seen before in QSO spectra. In addition to very broad high-ionization troughs of $\mathrm{C}$ IV and $\mathrm{Si}$ IV, it exhibits an extensive system of low ionization absorptions which include saturated lines of $\mathrm{Mg}$ II, Al II, and Al III, and broad Fe II features which have clear evidence for absorption from excited fine structure levels up to $0.12 \mathrm{eV}$. Even more remarkable are the very probable identifications of $\mathrm{Fe}$ II absorption by UV multiplets 62, 63, and 64 which require lower level excitations of $1.1 \mathrm{eV}$ and Fe III absorption by the triplet UV 34 from a lower level at $3.7 \mathrm{eV}$. These are the first reports of absorption from such highly excited levels in any QSO. Detailed studies of this QSO should provide new insight on the Fe II ionization zones in QSOs and place severe constraints on models for BAL QSOs.

Subject heading: quasars
\end{abstract}

\section{INTRODUCTION}

The broad absorption lines (BAL), which characterize the BAL QSOs, have widths which can exceed $30,000 \mathrm{~km} \mathrm{~s}^{-1}$ $(0.1 \mathrm{c})$ and the most prominent of them arise in highly ionized material. Both of these features suggest that the absorbing material is accelerated in the immediate neighborhood of the QSO. Broad absorption lines are seen in only a small fraction $(\sim 10 \%)$ of QSOs, but the covering factor of the absorbing clouds is probably less than $10 \%$ (Turnshek et al. 1980; Junkkarinen 1983) so that the BAL phenomenon could well be aspect-dependent and intrinsic to all QSOs. If this is indeed the case, an understanding of the BAL phenomenon is essential to the construction of realistic models for the distribution and ionization of gas around QSOs in general.

We report here the discovery and preliminary spectroscopy of a remarkable BAL QSO, 0059-2735, with an emission line redshift $z_{\mathrm{em}}=1.595$, which we believe will be of particular importance in setting up such models. In addition to the broad, high-ionization absorption troughs characteristic of this class of QSO, 0059-2735 exhibits corresponding absorptions at $z_{\mathrm{ab}}=1.581$ associated with low ionization species, including optically thick Mg II, Al II, and Al III, and broad Fe II, none of which has been seen before at these strengths in a QSO spectrum. Even more remarkable are several narrow absorption features at the same redshift, which we have identified with $\mathrm{N}$ I, $\mathrm{Fe}$ II, and $\mathrm{Fe}$ III arising from excited levels up to $3.7 \mathrm{eV}$. Furthermore the emission lines of $\mathrm{C}$ IV, $\mathrm{Mg}$ II, $\mathrm{Al}$ III, and Fe II are unusually narrow.

This rich complex spectrum with its wide range of ionizations and line widths, including the narrow Fe II absorption lines, provides the opportunity for a more detailed study of the physical conditions and the structure of the ionization zones in the gas surrounding a QSO than has hitherto been possible.

\section{THE OBJECTIVE PRISM SPECTRUM}

The QSO 0059-2735 was recognized as a particularly interesting object during a search of a glass copy of an unfiltered and untrailed hypersensitized IIIa-J objective-prism plate obtained with the UK Schmidt Telescope (UKST). The prism plate (UJ 3682P) centered on R.A. $00^{\mathrm{h}} 53^{\mathrm{m}}$. 0 , Decl. $-28^{\circ} 03^{\prime}$ (1950.0) was taken on 1977 October 17 using the lowdispersion 44' objective prism (Nandy et al. 1977) with an exposure of 70 minutes. Despite very heavy absorption in its blue continuum, $0059-2735$ is one of the brightest QSOs on the plate with $m(R)=17.1$, although it was not noted in earlier QSO surveys in this region (Boyle et al. 1985; Campusano and Torres 1983; Clowes and Savage 1983). Its position, as measured on the Cambridge Coradograph to an accuracy of $1^{\prime \prime}$, is R.A. $00^{\mathrm{h}} 59^{\mathrm{m}} 52^{\mathrm{s}}$.5, Decl. $-27^{\circ} 35^{\prime} 57^{\prime \prime}$.9 (1950.0). A finding chart will be published in the IIIa-J survey of the south Galactic pole by Hazard and R. G. McMahon.

Figure 1 (Plate 2) shows a reproduction of the objective prism spectrum on which we have marked the main features that led to its discovery and from which we estimated the redshift as $z_{\text {prism }}=1.62 \pm 0.03$. This redshift is close to the lower limit at which BAL QSOs can be recognized on objective prism plates by their high ionization absorption troughs (Hazard et al. 1984). However, it is probable that this particular object would have been noted as interesting at a lower redshift because of the narrower absorptions to the red of C IV of which the $\mathrm{Al}$ II and $\mathrm{Al}$ III lines are the most prominent. The wavelengths and corresponding redshifts of the main absorp- 
TABLE 1

MEASUREMENTS OF THE REDSHIFT OF 0059-2735 FROM the Objective Prism Spectrum

\begin{tabular}{ccc}
\hline \hline Observed edge & Identification & Redshift \\
\hline$\lambda_{\text {obs }}(\AA) \ldots \ldots \ldots \ldots$ & $\lambda_{\text {lab }}(\AA)$ & $z_{p}$ \\
$4880 \pm 40 \ldots \ldots \ldots$ & Al III 1857 & $1.63 \pm 0.02$ \\
$4450 \pm 30 \ldots \ldots \ldots$ & Al II 1671 & $1.66 \pm 0.02$ \\
$4020 \pm 20 \ldots \ldots \ldots$ & C IV 1549 & $1.60 \pm 0.01$ \\
$3640 \pm 13 \ldots \ldots \ldots$ & Si IV 1397 & $1.61 \pm 0.01$ \\
& Weighted mean & $1.61 \pm 0.01$ \\
\hline
\end{tabular}

tion features as measured from the prism spectrum are given in Table 1. It was the identification of the aluminum lines from these measurements which led us to select $0059-2735$ as a prime case for follow-up spectroscopy from more than 500 QSO candidates in the catalog of Hazard and McMahon (1988). Because these lines do not show as well on the reproduction as on the plate itself, we have included Figure 2, which reproduces tracings of the prism spectra made with the SERC Cambridge Automated Photographic Measuring (APM) Facility (Kibblewhite et al. 1984) and the prism reduction system (PRS) (Hewett et al. 1985).

\section{THE SLIT SPECTROSCOPY}

The slit spectrum shown in Figure 3 was obtained on 1985 June 22 by the $3.9 \mathrm{~m}$ Anglo-Australian Telescope (AAT) using the $82 \mathrm{~cm}$ camera of the RGO Spectrograph with a 1".0 slit, a 250 line $\mathrm{mm}^{-1}$ grating, and the image photon counting system (IPCS). This $5200 \mathrm{~s}$ exposure covered the spectral range 3340$5400 \AA$, close to that of the IIIa-J prism plate. The spectrum has been smoothed to an effective resolution of $10 \AA$. Further AAT observations of the same spectral region at similar resolution were obtained with the $25 \mathrm{~cm}$ camera, a 1."0 slit, and the 250 line $\mathrm{mm}^{-1}$ grating in a $1000 \mathrm{~s}$ exposure on 1985 August 26 , and a smaller region from 3980 to $4900 \AA$ was studied with the same camera, a 0.85 slit, and a 1200 line $\mathrm{mm}^{-1}$ grating in a $1600 \mathrm{~s}$ exposure on 1985 September 4 . Although the last spectrum was rather noisy, reliable wavelengths were obtained for several features.
At longer wavelengths a spectrum from 5300 to $10,000 \AA$ was obtained simultaneously with the blue one on 1985 August 26 on the AAT through the same slit but using a dichroic and the faint object red spectrograph (FORS) with a GEC chargecoupled device. As no standard star spectrum was available longward of $7000 \AA$ the uncorrected plot, which has a resolution of $20 \AA$, is shown in Figure 4 .

Table 2 lists the wavelengths of the emission and absorption features measured on each spectrum and the adopted means. For the strong, broad troughs the measurements were made to the $50 \%$ level of the red edges and also at the central positions of their minima. For the weaker lines only the positions of the minima were measured. In more than half the cases where multiple observations are available, the wavelengths agree within $3 \AA$. Consequently, in forming the means in column (5), it seemed worthwhile to add the correction between 1.0 and 2.0 $\AA$ to get vacuum values.

\section{LINE IDENTIFICATIONS}

\section{a) General Remarks}

The lower wavelength limit of our spectra precluded the observation of $\mathrm{N} v$ but the high ionization trough of $\mathrm{C}$ IV and much of that of Si IV are prominent in Figure 3. These troughs are typical of extreme BAL QSOs; the steep red edges recover gradually to the blue, with the $\mathrm{C}$ IV trough returning to the undisturbed continuum level close to the $\mathrm{Si}$ IV emission. There is evidence of structure within the C IV trough while the recovery of the $\mathrm{Si}$ IV trough is interrupted by strong absorptions of C II and Si II, which are both rare features in BAL QSO spectra. It is notable that the red edges of the high ionization troughs fall to zero at a rate determined by the width of the smoothing function. The associated $\mathrm{C}$ IV and $\mathrm{Si}$ IV $+\mathrm{O}$ IV] emission lines are weak and narrow.

To the red of the $\mathrm{C}$ IV absorption edge the dominant features are the $\mathrm{Al}$ II and $\mathrm{Al}$ III absorptions. These have the same steep red edges as the $\mathrm{C}$ IV and $\mathrm{Si}$ IV troughs but are much narrower overall showing that the low ionization material is confined to the lowest velocity region where the high ionization troughs are deepest. At the longer wavelengths in Figure 4, the spec-

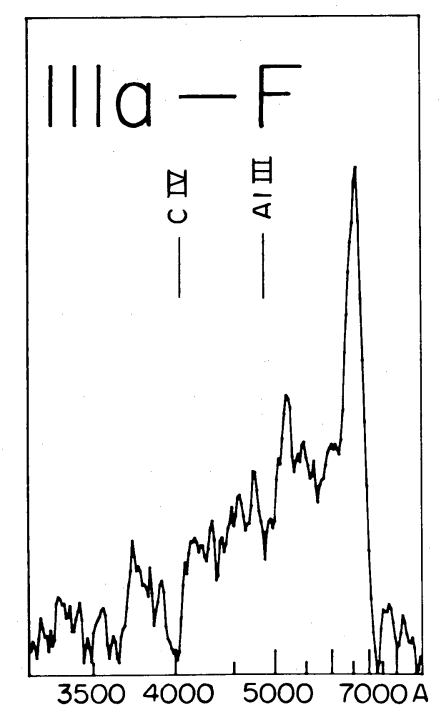

FIG. 2.-Tracings of the IIIa-J and IIIa-F objective-prism spectra of 0059-2735 made using the Cambridge APM, as descrived by Hewett et al. (1985). The vertical scale is APM intensity, and the absorptions are identified. 


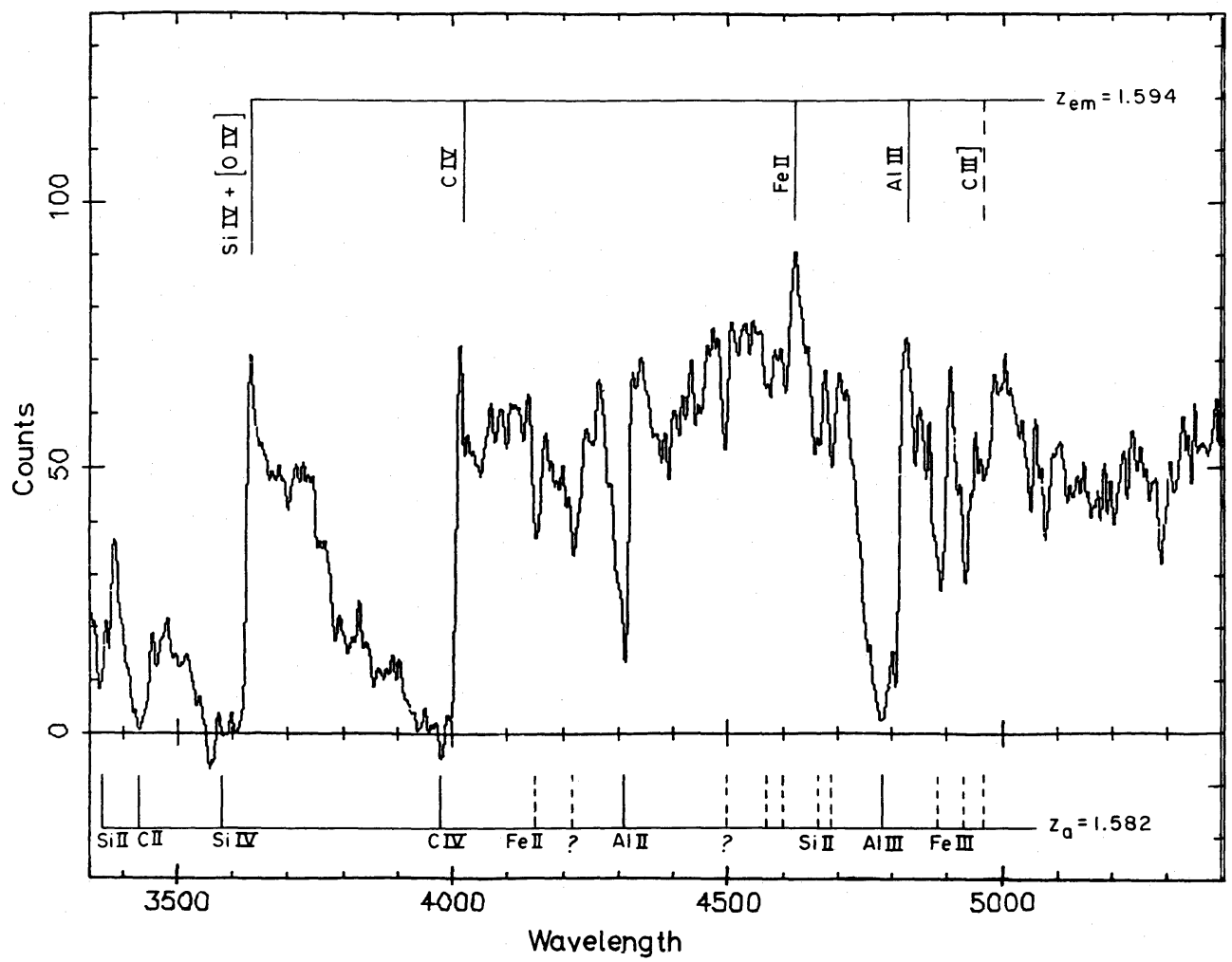

Fig. 3. - The blue spectrum of $0059-2735$ from 3340 to $5400 \AA$ reduced to a relative-intensity scale. The emission lines are indicated by solid lines in the upper part of the figure with the expected position of $\mathrm{C} \mathrm{III]} \mathrm{marked} \mathrm{by} \mathrm{a} \mathrm{broken} \mathrm{line.} \mathrm{The} \mathrm{absorptions} \mathrm{are} \mathrm{indicated} \mathrm{by} \mathrm{lines} \mathrm{below} \mathrm{the} \mathrm{spectrum.} \mathrm{The} \mathrm{solid} \mathrm{lines} \mathrm{mark} \mathrm{the}$ strong broad troughs whose redshifts are deduced in Table 5 and the broken lines mark narrow features whose identifications are presented in Table 6.

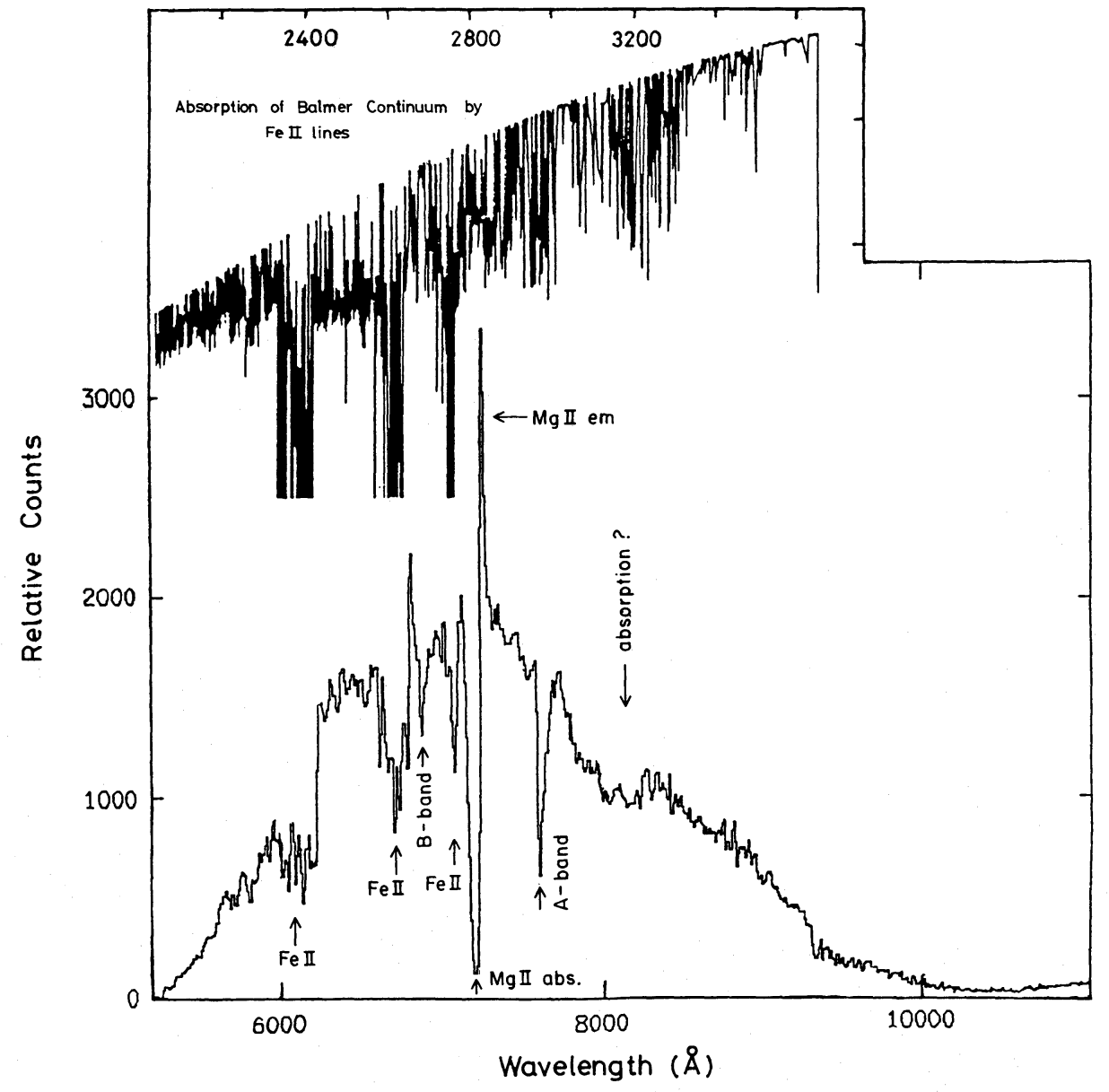

FIG. 4.-The lower figure shows the spectrum of $0059-2735$ between 5300 and $10,000 \AA$ uncorrected for the instrument sensitivity, and the upper figure shows the absorption of an optically thin Balmer continuum by Fe II lines as calculated by Wills, Netzer, and Wills (1985). Their scale of rest wavelengths at the top has been adjusted to match the three observed absorption troughs attributed to $\mathrm{Fe}$ II. 
TABLE 2

Wavelength Measurements in Slit SPECTRA OF 0059-2735

\begin{tabular}{|c|c|c|c|c|c|}
\hline $\begin{array}{l}\text { Feature } \\
\text { (1) }\end{array}$ & $\begin{array}{c}1985 \\
\text { Jun } 22 \\
\text { air }(\AA) \\
(2)\end{array}$ & $\begin{array}{c}1985 \\
\text { Aug } 26 \\
\operatorname{air}(\AA) \\
(3)\end{array}$ & $\begin{array}{c}1985 \\
\text { Sep } 4 \\
\operatorname{air}(\AA) \\
(4)\end{array}$ & $\begin{array}{c}\text { Adopted } \\
\text { Vacuum }(\AA) \\
(5)\end{array}$ & $\begin{array}{l}\text { Ion } \\
(6)\end{array}$ \\
\hline $\begin{array}{l}\text { Abs minimum } \ldots \ldots \ldots \ldots \\
\text { Abs edge } \ldots \ldots \ldots \ldots \ldots \\
\text { Abs minimum } \ldots \ldots \ldots \ldots \\
\text { Abs edge } \ldots \ldots \ldots \ldots \ldots \ldots \\
\text { Abs minimum } \ldots \ldots \ldots \ldots\end{array}$ & $\begin{array}{l}3359 \\
3375 \\
3430 \\
3448 \\
3584\end{array}$ & $\begin{array}{c}\cdots \\
\cdots \\
3433 \\
3449 \\
3574\end{array}$ & $\begin{array}{l}\cdots \\
\cdots \\
\cdots \\
\cdots \\
\cdots\end{array}$ & $\begin{array}{l}3360 \\
3376 \\
3432 \\
3449 \\
3580\end{array}$ & $\begin{array}{l}\text { Si II } \\
\text { Si II } \\
\text { C II } \\
\text { C II } \\
\text { Si IV }\end{array}$ \\
\hline $\begin{array}{l}\text { Abs edge } \ldots \ldots \ldots \ldots \ldots \\
\text { Emission } \ldots \ldots \ldots \ldots \ldots \ldots \\
\text { Abs minimum } \ldots \ldots \ldots \ldots \\
\text { Abs edge } \ldots \ldots \ldots \ldots \ldots \ldots \\
\text { Emission } \ldots \ldots \ldots \ldots \ldots \ldots\end{array}$ & $\begin{array}{l}3624 \\
3633 \\
3971 \\
4005 \\
4014\end{array}$ & $\begin{array}{c}3627 \\
\ldots \\
3954^{a} \\
4004 \\
4014\end{array}$ & $\begin{array}{c}\cdots \\
\cdots \\
4008 \\
4012\end{array}$ & $\begin{array}{l}3627 \\
3634 \\
3972 \\
4007 \\
4014\end{array}$ & $\begin{array}{l}\text { Si IV } \\
\text { Si IV } \\
\text { C IV } \\
\text { C IV } \\
\text { C IV }\end{array}$ \\
\hline $\begin{array}{l}\text { Narrow abs } \ldots \ldots \ldots \ldots \\
\text { Narrow abs } \ldots \ldots \ldots \ldots \ldots \\
\text { Abs minimum } \ldots \ldots \ldots \ldots \\
\text { Abs edge } \ldots \ldots \ldots \ldots \ldots \ldots \\
\text { Narrow abs } \ldots \ldots \ldots \ldots \ldots\end{array}$ & $\begin{array}{l}4153 \\
4219 \\
4311 \\
4319 \\
4493\end{array}$ & $\begin{array}{c}\ldots \\
4216 \\
4312 \\
4319 \\
4491\end{array}$ & $\begin{array}{c}\cdots \\
\ldots 312 \\
4321 \\
\cdots\end{array}$ & $\begin{array}{l}4154 \\
4219 \\
4313 \\
4321 \\
4493\end{array}$ & $\begin{array}{l}\text { Fe II } \\
\text { Fe II } \\
\text { A1 II } \\
\text { A1 II } \\
\text { N I }\end{array}$ \\
\hline $\begin{array}{l}\text { Narrow abs } \ldots \ldots \ldots \ldots \\
\text { Narrow abs } \ldots \ldots \ldots \ldots \ldots \\
\text { Emission } \ldots \ldots \ldots \ldots \ldots \ldots \\
\text { Narrow abs } \ldots \ldots \ldots \ldots \ldots \\
\text { Narrow abs } \ldots \ldots \ldots \ldots \ldots\end{array}$ & $\begin{array}{l}4572 \\
4604 \\
4622 \\
4660 \\
4688\end{array}$ & $\begin{array}{l}4577 \\
4609 \\
4622 \\
4671 \\
4687\end{array}$ & $\begin{array}{c}4580 \\
4608 \\
4624 \\
\cdots \\
\cdots\end{array}$ & $\begin{array}{l}4578 \\
4608 \\
4624 \\
4667 \\
4689\end{array}$ & $\begin{array}{l}? \\
\text { Fe II } \\
\text { Fe II } \\
\text { Si II } \\
\text { Si II }\end{array}$ \\
\hline $\begin{array}{l}\text { Abs minimum } \ldots \ldots \ldots \ldots \\
\text { Abs edge } \ldots \ldots \ldots \ldots \ldots \\
\text { Emission } \ldots \ldots \ldots \ldots \ldots \ldots \\
\text { Narrow abs } \ldots \ldots \ldots \ldots \ldots \\
\text { Narrow abs } \ldots \ldots \ldots \ldots \ldots\end{array}$ & $\begin{array}{l}4780 \\
4812 \\
4824 \\
4888 \\
4933\end{array}$ & $\begin{array}{l}4782 \\
4813 \\
4830 \\
4879 \\
4924\end{array}$ & $\begin{array}{c}4785 \\
4813 \\
\cdots \\
\cdots \\
\cdots\end{array}$ & $\begin{array}{l}4784 \\
4814 \\
4828 \\
4885 \\
4930\end{array}$ & $\begin{array}{l}\text { A1 III } \\
\text { A1 III } \\
\text { A1 III } \\
\text { Fe III } \\
\text { Fe III }\end{array}$ \\
\hline $\begin{array}{l}\text { Narrow abs } \ldots \ldots \ldots \ldots \\
\text { Emission } \ldots \ldots \ldots \ldots \ldots \ldots \\
\text { Abs center } \ldots \ldots \ldots \ldots \ldots \\
\text { Abs edge } \ldots \ldots \ldots \ldots \ldots \ldots \\
\text { Narrow abs } \ldots \ldots \ldots \ldots \ldots\end{array}$ & $\begin{array}{c}4964 \\
5003: \\
\cdots \\
\cdots \\
\cdots\end{array}$ & $\begin{array}{c}4956 \\
\ldots \\
6116: \\
6231 \\
6612\end{array}$ & $\begin{array}{l}\cdots \\
\cdots \\
\cdots \\
\cdots \\
\cdots\end{array}$ & $\begin{array}{l}4961 \\
5004: \\
6118 \\
6233 \\
6614\end{array}$ & $\begin{array}{l}\text { Fe III } \\
\text { C III]? } \\
\text { Fe II } \\
\text { Fe II } \\
\text { Fe II }\end{array}$ \\
\hline $\begin{array}{l}\text { Abs center } \ldots \ldots \ldots \ldots \ldots \\
\text { Abs edge } \ldots \ldots \ldots \ldots \ldots \ldots \\
\text { Emission } \ldots \ldots \ldots \ldots \ldots \ldots \\
\text { Abs minimum } \ldots \ldots \ldots \ldots \\
\text { Abs edge } \ldots \ldots \ldots \ldots \ldots \ldots\end{array}$ & $\begin{array}{l}\cdots \\
\cdots \\
\cdots \\
\cdots \\
\cdots\end{array}$ & $\begin{array}{l}6718 \\
6798 \\
6814 \\
7079 \\
7103\end{array}$ & $\begin{array}{l}\cdots \\
\cdots \\
\cdots \\
\cdots \\
\cdots\end{array}$ & $\begin{array}{l}6720 \\
6800 \\
6816 \\
7081 \\
7105\end{array}$ & $\begin{array}{l}\mathrm{Fe} \text { II } \\
\mathrm{Fe} \text { II } \\
\mathrm{Fe} \text { II } \\
\mathrm{Fe} \text { II } \\
\mathrm{Fe} \text { II }\end{array}$ \\
\hline $\begin{array}{l}\text { Abs minimum } \ldots \ldots \ldots \ldots \\
\text { Abs edge } \ldots \ldots \ldots \ldots \ldots \\
\text { Emission } \ldots \ldots \ldots \ldots \ldots \ldots\end{array}$ & $\begin{array}{l}\cdots \\
\cdots \\
\cdots\end{array}$ & $\begin{array}{l}7204 \\
7242 \\
7261\end{array}$ & $\begin{array}{l}\cdots \\
\cdots \\
\cdots\end{array}$ & $\begin{array}{l}7206 \\
7244 \\
7263\end{array}$ & $\begin{array}{l}\mathrm{Mg} \text { II } \\
\mathrm{Mg} \text { II } \\
\mathrm{Mg} \text { II }\end{array}$ \\
\hline
\end{tabular}

a Center of broad absorption; no clear minimum on this spectrum.

trum is dominated by the emission and absorption of $\mathrm{Mg}$ II and two wide absorptions which we shall identify with $\mathrm{Fe}$ II.

In the analysis that follows we have adopted wavelengths $\lambda_{\text {lab }}$ and transition probabilities $A_{u l}$ from Morton and Smith (1973) or Morton (1978), supplemented by the publications of the National Bureau of Standards. The exceptions are Fe II and Fe III where we have taken wavelengths from Johansson (1978), Kelly (1979), or Kelly and Palumbo (1973) and oscillator strengths $g f$ from the calculations of Kurucz (1981) and Kurucz and Peytremann (1975). We realize that such calculations can have considerable errors, particularly for weak lines, but in most cases no other data on transition probabilities are available.

\section{b) Emission Lines}

The identification of the emission lines of Si IV + O IV], C IV, $\mathrm{Al} \mathrm{III,} \mathrm{and} \mathrm{Mg}$ II in Table 3 is straightforward. However the lines at $4624 \pm 1 \AA$ and $6816 \pm 5 \AA$ need further discussion. If the redshift is $z=1.595 \pm 0.003$, the corresponding rest wavelengths are $1781.9 \pm 1.8 \AA$ and $2627 \pm 4 \AA$ in vacuum. Some possibilities for these lines are listed in Table 4.
Fe II UV67 at $\lambda 1781.704$ fits very well, but this is a weak intersystem line with a transition probability $A=1.5 \times 10^{5}$ $\mathrm{s}^{-1}$. The upper level more likely would decay through UV 106 $\lambda \lambda 2153.0,2177.7$; UV $133 \lambda 2298.9$ or UV $221 \lambda \lambda 2562.9,2640.4$ whose transition probabilities range from $2.0 \times 10^{8}$ to $0.2 \times 10^{8} \mathrm{~s}^{-1}$. A much better candidate is the triplet Fe II UV191 at $\lambda \lambda 1785.272,1786.752,1787.996$ each with $A=14 \times 10^{8} \mathrm{~s}^{-1}$. The only competing transition is UV9 to the ground term, with nine components between $\lambda 1260.5$ and $\lambda 1277.6$ and a maximum $A=1.7 \times 10^{8} \mathrm{~s}^{-1}$. Our observed FWHM of $12 \AA$ or $4.6 \AA$ at rest well exceeds the triplet width, but the mean wavelength weighted by $g_{u} A_{u l}$ is $\lambda 1786.37$, which is somewhat outside our expected range of 1780.1 to $1783.7 \AA$. The wavelength of S I UV13 at $\lambda 1782.263$ would fit well, but this ion is expected to have a significantly lower abundance that Fe II whose UV191 multiplet has nearly 10 times the transition probability. Some of the 10 lines of O III UV19.55 $3 d^{3} F^{o}-4 f F[5 / 2,7 / 2]$ fall within the acceptable wavelength range, but these are weak transitions, and cover a total range of $13.8 \AA$. We are not aware of any other plausible transitions among the cosmically abundant elements. One lower abundance candidate might be P I UV1 at $\lambda \lambda 1774.99,1782.87$, 1787.68 with $g_{u} A_{u l}=13.9 \times 10^{8}, 9.2 \times 10^{8}$, and $4.5 \times 10^{8} \mathrm{~s}^{-1}$, but the $12.7 \AA$ range again is too large, and the abundance is expected to be even lower than $S_{I}$. Thus our preferred identification for the emission at $4624 \AA$ is the Fe II triplet UV191. It is this transition that Selvelli and Hack (1985) identified in the symbiotic star $\mathrm{CH}$ Cyg and Hartig and Baldwin (1986) believed is present in emission in the QSO 0335-336.

We are less certain about the identification of the emission line at $6816 \AA$. If $z_{\text {em }}=1.595$ the rest wavelength would be $2626.6 \AA$ in vacuum. The strong Fe II multiplet UV1 with lines from 2586.6 to $2632.1 \AA$ is a candidate, particularly if all emission lines shortward of the edge at $6800 \AA$ or $2620.4 \AA$ at rest, are obliterated. The remaining lines lie between 2621.2 and $2632.1 \AA$ consistent with the observed width, and their mean wavelength weighted by $g_{u} A_{u l}$ is $2629.7 \AA$. Higher resolution spectra are needed to check for the multiple components expected if the emission lines at 4624 and $6816 \AA$ are actually Fe II.

There is heavy absorption over the expected position of the C III] $\lambda 1909$ emission line, but the peak centered on $5003 \AA$ could correspond to its red wing. In that case $\mathrm{C}$ III] would be by far the widest emission line in the spectrum.

\section{c) Broad Absorption Lines}

Table 5 gives the vacuum wavelengths of both the centers of the trough minima $\left(\lambda_{M}\right)$ and the steep red edges $\left(\lambda_{R}\right)$, along with the redshifts of the suggested identifications. The redshifts of the minima $\left(z_{M}\right)$ for multiplets have been calculated using the weighted means of the wavelengths $\left\langle\lambda_{\text {lab }}\right\rangle$ of the unsaturated components, while the redshifts of the edges $\left(z_{R}\right)$ have been derived from the wavelengths of the redmost component of each system. The most straightforward identifications are with absorptions from the ground levels of Si IV, C IV, Al II, Al III, and $\mathrm{Mg}$ II. The excellent agreement among red components confirms that the absorption edges extend over only a few angstroms. The other transitions that can be matched, namely the resonance lines of $\mathrm{Si}$ II and $\mathrm{C}$ II and the three multiplets of Fe II, need a more detailed discussion.

In the case of $\mathrm{Fe}$ II the red edges fit best with the longest wavelength components of UV2 at 2414.0 and UV1 at 2632.1 $\AA$. These lines arise from fine-structure levels excited to 977.1 
TABLE 3

EMisSiOn Lines IN THE SPECTRUM OF 0059-2735

\begin{tabular}{|c|c|c|c|c|c|}
\hline \multirow{2}{*}{$\begin{array}{c}\text { OBSERVED } \\
\text { WAVELENGTH } \\
\lambda_{\text {obs }}\end{array}$} & \multicolumn{2}{|c|}{ IDENTIFICATION } & \multirow{2}{*}{$\begin{array}{l}\text { REDSHIFT } \\
z_{\text {em }}\end{array}$} & \multicolumn{2}{|c|}{ 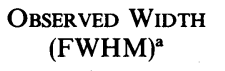 } \\
\hline & Ion & $\lambda_{\mathrm{lab}}(\AA)$ & & $(\AA)$ & $\left(\mathrm{km} \mathrm{s}^{-1}\right)$ \\
\hline \multicolumn{6}{|c|}{ A Lines from Blue Spectrum-Fig. 4} \\
\hline 3634 & $\mathrm{Si}$ IV + $\left.\mathrm{O}_{\text {IV }}\right]$ & 1399.7 & 1.596 & 10 & 820 \\
\hline $4014 \ldots \ldots \ldots \ldots$ & $\mathrm{C}_{\text {IV }}$ & 1549.0 & 1.591 & 10 & 750 \\
\hline $4624 \ldots \ldots \ldots \ldots \ldots$ & $\mathrm{Fe}$ II & UV $191,1786.4$ & $1.588^{\mathrm{b}}$ & 12 & 780 \\
\hline $4828 \ldots \ldots \ldots \ldots$ & $\mathrm{Al}$ III & 1857.4 & 1.599 & 19 & 1200 \\
\hline 5004: $\ldots \ldots \ldots \ldots$ & $\mathrm{C}$ III] & 1908.7 & $1.622:^{b}$ & 42 & 2500 \\
\hline \multicolumn{6}{|c|}{ B Lines from Red Spectrum-Fig. 5} \\
\hline $6818 \ldots \ldots \ldots \ldots \ldots$ & $\mathrm{Fe}$ II & UV 12629.8 & $1.593^{\mathrm{b}}$ & 30 & 1300 \\
\hline $7263 \ldots \ldots \ldots \ldots$ & $\mathrm{Mg}_{\text {II }}$ & 2798.7 & 1.595 & 20 & 830 \\
\hline Average $z^{\mathrm{b}} \ldots$ & & $1.595 \pm 0.003$ & & & \\
\hline
\end{tabular}

TABLE 4

Possible IdENTIFICATIONS OF THE EMISSION LiNe AT $4624 \AA$

\begin{tabular}{|c|c|c|c|c|c|c|c|}
\hline Ion & No. & Transition & $g_{l}$ & $g_{u}$ & $\begin{array}{c}\lambda \\
(\AA)\end{array}$ & $\log g f$ & $\begin{array}{c}A_{\mathrm{ul}} \\
\left(\mathrm{s}^{-1}\right)\end{array}$ \\
\hline $\mathrm{Fe}$ II] & UV 67 & $a^{4} D-z^{2} P^{o}$ & 4 & 2 & 1781.704 & -3.844 & $1.5 \times 10^{5}$ \\
\hline \multirow[t]{3}{*}{$\mathrm{Fe}$ II } & UV $191^{a}$ & $a^{6} S-x^{6} P^{o}$ & 6 & 8 & 1785.272 & 0.743 & $14 \times 10^{8}$ \\
\hline & & & 6 & 6 & 1786.752 & 0.619 & $14 \times 10^{8}$ \\
\hline & & & 6 & 4 & 1787.996 & 0.444 & $14 \times 10^{8}$ \\
\hline $\mathrm{S}_{\mathrm{I}} \ldots \ldots \ldots \ldots \ldots$ & UV 13 & $3 p^{4}{ }^{1} S-4 s^{1} P^{o}$ & 1 & 3 & 1782.263 & -0.66 & $1.5 \times 10^{8}$ \\
\hline
\end{tabular}

a The Fe II triplet UV 191 is preferred for reasons discussed in the text.

TABLE 5

The Strong Absorption Lines in the SPeCtrum OF 0059-2735

\begin{tabular}{|c|c|c|c|c|c|c|c|c|}
\hline \multicolumn{2}{|c|}{ Identification $\lambda_{\text {lab }}$} & \multirow{2}{*}{$\begin{array}{l}\lambda_{\text {lab }} \\
(\AA)\end{array}$} & \multirow{2}{*}{$\begin{array}{l}\lambda_{M}{ }^{\mathrm{a}} \\
(\AA)\end{array}$} & \multirow{2}{*}{$\begin{array}{l}\lambda_{R}{ }^{\mathrm{a}} \\
(\AA)\end{array}$} & \multirow[b]{2}{*}{$z_{M}{ }^{\mathrm{a}}$} & \multirow[b]{2}{*}{$z_{R}^{\mathrm{a}}$} & \multirow{2}{*}{\multicolumn{2}{|c|}{$\begin{array}{l}\text { Total Width } \\
\left(\mathrm{km} \mathrm{s}^{-1}\right)\end{array}$}} \\
\hline$(\AA)$ & $(\AA)$ & & & & & & & \\
\hline \multicolumn{9}{|c|}{ A. Blue Spectrum-Fig. 3} \\
\hline Si II & $1304.4,1309.3$ & 1306.8 & 3360 & 3376 & 1.571 & 1.578 & & \\
\hline $\mathrm{C}_{\text {II }} \ldots . . .$. & $1334.5,1335.7$ & 1335.3 & 3432 & 3449 & 1.570 & 1.582 & 50 & 4400 \\
\hline Si IV ........ & $1393.8,1402.8$ & 1396.8 & 3580 & 3627 & 1.563 & 1.586 & 140 & 12000 \\
\hline C IV ............... & $1548.2,1550.8$ & 1549.0 & 3972 & 4007 & 1.564 & 1.584 & 260 & 20000 \\
\hline Al II .............. & 1670.8 & 1670.8 & 4313 & 4321 & 1.581 & 1.586 & 21 & 1500 \\
\hline Al III ...................... & $1854.7,1862.8$ & 1857.4 & 4784 & 4814 & 1.576 & 1.584 & 100 & 6300 \\
\hline \multicolumn{9}{|c|}{ B. Red Spectrum-Fig. 4} \\
\hline $\mathrm{Fe}_{\text {II }} \ldots \ldots \ldots \ldots \ldots$ & $\begin{array}{l}2328.1 \text { to } 2381.5 \text { UV3) } \\
2367.6 \text { to } 2414.0 \text { UV2) }\end{array}$ & & 6118 & 6233 & $\ldots$ & $1.582^{b}$ & 230 & 11000 \\
\hline Fe II .... & 2586.6 to 2632.1 UV1 & & 6720 & 6800 & & $1.583^{b}$ & 160 & 7100 \\
\hline Fe II .................... & $\begin{array}{c}2740.4 \text { to } 2765.5 \\
\text { UV62, } 63\end{array}$ & 2747 & 7081 & 7105 & $1.578^{b}$ & $1.578^{b}$ & 80 & 3400 \\
\hline Mg II ............ & $2796.3,2803.5$ & 2798.7 & 7206 & 7244 & 1.575 & 1.584 & 100 & 4200 \\
\hline Mean redshift ${ }^{\mathbf{b}}$ & & & & 1.572 & $\begin{array}{r}1.583 \\
\pm 0.006\end{array}$ & \pm .003 & & \\
\hline
\end{tabular}

a Subscripts $M$ and $R$ refer to the minimum and the red edge of each trough, respectively. The redshifts $z_{R}$ were calculated using the red component of each multiplet and the corresponding $z_{M}$ 's were calculated using the weighted means $\lambda_{\text {lab }}$ for unsaturated components.

${ }^{b}$ Since the effective wavelengths of the Fe II multiplets are uncertain, their redshifts were omitted from the mean. 
and $667.7 \mathrm{~cm}^{-1}$, respectively. The usual absorptions from the ground state at 2344.2 (UV3), 2367.6, 2374.5, 2382.8 (UV2), 2586.6 , and $2600.2 \AA$ (UV1) cannot explain the red edges of the profiles. They miss by $3700 \mathrm{~km} \mathrm{~s}^{-1}$ in each feature. Thus there is clear evidence for a considerable excitation of the fine structure levels in Fe II.

Similarly we should expect absorption from the excited finestructure levels of C II at $63.4 \mathrm{~cm}^{-1}$ and $\mathrm{Si}$ II at $287.3 \mathrm{~cm}^{-1}$. Therefore in calculating redshifts in Table 5 we have compared the red edges with the longest wavelength component in each multiplet and the observed minima with mean wavelengths, weighted by $g f$ as appropriate for unsaturated lines. However, we note that the $z_{R}$ derived from the wavelengths of just the transitions from the ground level are closer to the mean for the edges of $\mathrm{Si}$ IV, C IV, Al II, $\mathrm{Al}$ III, and $\mathrm{Mg}$ II (e.g., $z_{R}=1.588$ for $\mathrm{Si}$ II 1304.4 vs. 1.57 for $1309.3 \AA$ ). A higher resolution spectrum is needed to determine whether the absorption from the excited level is present.

If we identify the absorption trough between 6640 and 6800 $\AA$ with the UV1 Fe II lines from 2586.6 to 2632.1 at a redshift of 1.583 , the observed short wavelength edge is bluer by $41 \AA$ or $1800 \mathrm{~km} \mathrm{~s}^{-1}$ more than required by the multiplet. This velocity is comparable with the width of the Al II absorption, but less than that of $\mathrm{Mg}$ II. The trough between 6003 and $6233 \AA$ should have contributions from both UV3 between 2328.1 and $2381.5 \AA$ and UV2 between 2367.6 and $2414.0 \AA$ since each multiplet represents absorption from the ground term of Fe II. In this case the short wavelength edge is only $10 \AA$ or $500 \mathrm{~km}$ $\mathrm{s}^{-1}$ beyond the limit of the multiplet. It is unclear how much velocity gradient is present in the region of $\mathrm{Fe}$ II absorption, since some of the width of each trough could be the result of other absorption lines, including $\mathrm{Fe}$ II, arising from higher excited levels.

In this regard it is most interesting to compare our red spectrum with the calculation by Wills, Netzer, and Wills (1985) of the absorption of $15,000 \mathrm{~K}$ optically thin Balmer continuum emission passing through a model QSO zone of singly ionized Fe populated according to a Boltzmann distribution at a temperature of about $8000 \mathrm{~K}$. At the top of Figure 5 we have redshifted their spectrum to fit our observation. The correlation between the two spectra leaves no doubt that blends of Fe II multiplets can explain both the widths and shapes of much of the observed absorption blueward of $\mathrm{Mg}$ II. Furthermore, alignment of the two wavelength scales gives a redshift of $z=1.580$ for the Fe II systems, in excellent agreement with the average value of $z=1.583$ found for the red edges of the high ionization troughs.

The excellent match between the spectra in Figure 5 depends on the two troughs identified with the resonance transitions of $\mathrm{UV} 1, \mathrm{UV} 2$, and UV3 and a narrower feature at a rest wavelength $7081 / 2.581=2744 \AA$. There are no resonance transitions of $\mathrm{Fe}$ II near this wavelength; the lines in the calculated spectrum must be from multiplets UV62 $a^{4} D-z^{4} F^{o}$ and UV63 $a^{4} D-z^{4} D^{0}$ whose strongest lines are $2756.5,2750.1,2740.4$, $2747.3,2747.8$ and 2744.0, with lower levels excited by 0.98 to $1.09 \mathrm{eV}$. If the vacuum wavelengths of all 19 lines in the two multiplets are weighted by $g f$, the mean is $2747 \AA$. A feature in our spectrum between 7940 and $8240 \AA$ also might be due partly to Fe II absorption.

However, before we accept such unusual excitation in a QSO absorption system we must exclude resonance transitions in other ions. According to the finding list of Morton and Smith (1973) the only known transitions of abundant elements are UV1 of V II and UV5 of Fe I, but both of these have stronger lines separate from those near $2745 \AA$. We conclude that ionized iron is present with excitation up to $1.1 \mathrm{eV}$ ! This is the first example of such excitation in QSO absorption lines.

\section{d) Narrow Absorption Lines}

Now that we have concluded absorptions can occur from excitations up to $1.1 \mathrm{eV}$, a wide set of possibilities exists for identifying the narrow lines listed in Table 6. Therefore in column (2) we have calculated the rest wavelengths for a redshift $z=1.581$ appropriate for the center of the Al II line. Thus the narrow line at $6614 \AA$ appears to be a blend of the three shortest wavelength components of Fe II UV $64 a^{4} D-z{ }^{4} P^{o}$; its remaining members all would be lost in the trough on the red side. The line at 4578 could be the intersystem transition $\mathrm{Fe}$ II] UV67 $a^{4} D-z^{2} P^{o}$ from the same lower term, though the calculated oscillator strength is rather weak to make this identification convincing.

Resonance lines of Fe II UV8 and Si II UV1 can account for lines observed at 4154 and $4667 \AA$ and fine-structure excitation of these same ions for lines at 4219 and 4689 . However it is puzzling why other components of Fe II UV8 are not clearly seen. Absorptions from higher levels of Fe II such as UV43 at $0.23 \mathrm{eV}$ may be contributing.

The remaining lines at $4493,4608,4885,4930$, and $4961 \AA$ present the most surprising result. The last three match reasonably well with the Fe III triplet UV34, but the lower level requires an excitation of $30088.8 \mathrm{~cm}^{-1}$ or $3.73 \mathrm{eV}$ !! This is a metastable level with no efficient decays to lower levels so that it could have a significant population. If absorption from such a high level is possible, the line at $4493 \AA$ could be identified with $\mathrm{N}_{\mathrm{I}}$ UV9 at $3.58 \mathrm{eV}$ and the one at $4608 \AA$ with Fe II UV191 from $2.89 \mathrm{eV}$. In these cases the lower levels also are metastable. Contrary to our previous experience with QSO absorption lines, we are obliged to take seriously at least the Fe III identification unless higher resolution observations show that the wavelength ratios do not match. Hartig and Baldwin (1986) reported this Fe III triplet in the QSO 0335-336 in emission, but it never has been mentioned in a QSO absorption spectrum.

\section{SUMMARY AND DISCUSSION}

The BAL QSO 0059-2735 is remarkable in many ways.

1. With the possible exception of the intersystem transition of $\mathrm{C} \mathrm{III],} \mathrm{all} \mathrm{of} \mathrm{the} \mathrm{emission} \mathrm{lines} \mathrm{are} \mathrm{extremely} \mathrm{narrow.} \mathrm{Three}$ of the lines-Si IV, C IV, and $\mathrm{Mg}$ II-are unresolved in our spectra and have observed FWHM $\leq 800 \mathrm{~km} \mathrm{~s}^{-1}$. Presumably these are underestimates of the true widths because of the strong absorptions on the blue sides. However the steep red profiles imply that the lines must be intrinsically narrow and that their true widths at half maximum do not exceed $2000 \mathrm{~km}$ $\mathrm{s}^{-1}$. In any case the total width of the $\mathrm{Mg}$ II emission does not exceed the total width of the $\mathrm{Mg}$ II absorption trough, which is about $4000 \mathrm{~km} \mathrm{~s}^{-1}$.

2. The spectrum includes two prominent emission lines identified with Fe II multiplets UV1 $a^{6} D \leftarrow z^{6} D^{\circ}$ and UV191 $a^{6} S \leftarrow x^{6} P^{0}$. The first has not been reported previously in QSOs and the second only in $0335-336$. These lines contrast with the many broad, weak features in some QSOs that Wills, Netzer, and Wills (1980) have suggested are caused by numerous Fe II multiplets.

3. The Si IV and C IV absorptions are extremely broad with terminal velocities as large as $20,000 \mathrm{~km} \mathrm{~s}^{-1}$ or $0.067 c$ and they 
TABLE 6

NARROW ABSORPTION LINES IN 0059-2735

\begin{tabular}{|c|c|c|c|c|c|c|c|c|c|}
\hline $\begin{array}{c}\lambda_{\mathrm{obs}} \\
\operatorname{vac}(\AA) \\
(1)\end{array}$ & $\begin{array}{c}\lambda_{\text {rest }} \mathbf{a} \\
\operatorname{vac}(\AA) \\
(2)\end{array}$ & $\begin{array}{l}\text { Ion } \\
\text { (3) }\end{array}$ & $\begin{array}{l}\text { UV } \\
\text { No } \\
(4)\end{array}$ & $\begin{array}{c}\lambda_{\mathrm{lab}} \\
\operatorname{vac}(\AA) \\
(5)\end{array}$ & $\begin{array}{c}\text { Transition } \\
\text { (6) }\end{array}$ & $\begin{array}{c}g_{1} \\
(7)\end{array}$ & $\begin{array}{c}g_{\mathrm{u}} \\
(8)\end{array}$ & $\begin{array}{c}\mathrm{EP}_{l} \\
\left(\mathrm{~cm}^{-1}\right) \\
(9)\end{array}$ & $\begin{array}{c}\log g f \\
(10)\end{array}$ \\
\hline $4154 \ldots \ldots \ldots \ldots$ & 1609.4 & $\mathrm{Fe}$ II & 8 & $\begin{array}{l}1608.451 \\
1618.468 \\
1621.686 \\
1625.912 \\
1629.160 \\
1631.128\end{array}$ & $a^{6} D-y^{6} P^{o}$ & $\begin{array}{r}10 \\
8 \\
8 \\
6 \\
6 \\
6\end{array}$ & $\begin{array}{l}8 \\
8 \\
6 \\
8 \\
6 \\
4\end{array}$ & $\begin{array}{c}0 \\
384.8 \\
384.8 \\
667.7 \\
667.7 \\
667.7\end{array}$ & $\begin{array}{l}-0.290 \\
-0.832 \\
-0.598 \\
-1.610 \\
-0.745 \\
-1.061\end{array}$ \\
\hline $4219 \ldots$ & 1634.6 & $\{\mathrm{Fe}$ II & 8 & $\begin{array}{l}1634.350 \\
1636.331 \\
1639.401\end{array}$ & & $\begin{array}{l}4 \\
4 \\
2\end{array}$ & $\begin{array}{l}6 \\
4 \\
4\end{array}$ & $\begin{array}{l}862.6 \\
862.6 \\
977.1\end{array}$ & $\begin{array}{l}-1.228 \\
-0.885 \\
-1.030\end{array}$ \\
\hline $4493 \ldots \ldots \ldots \ldots$ & 1740.8 & $\mathrm{~N}_{\mathrm{I}}$ & 9 & $\begin{array}{l}1742.719 \\
1742.731 \\
1745.248 \\
1745.260\end{array}$ & $2 p^{3}{ }^{2} P^{o}-3 s^{2} P$ & $\begin{array}{l}2 \\
4 \\
2 \\
4\end{array}$ & $\begin{array}{l}4 \\
4 \\
2 \\
2\end{array}$ & $\begin{array}{l}28838.9 \\
28839.3 \\
28838.9 \\
28839.3\end{array}$ & $\begin{array}{l}-1.20 \\
-0.48 \\
-0.93 \\
-1.23\end{array}$ \\
\hline $4578 \ldots \ldots \ldots \ldots$ & 1773.7 & $\mathrm{Fe}$ II] & 67 & 1781.704 & $a^{4} D-z{ }^{2} P^{o}$ & 4 & 2 & 8680.5 & -3.844 \\
\hline $4608 \ldots$ & 1785.4 & $\mathrm{Fe}$ II & 191 & $\begin{array}{l}1785.272 \\
1786.752 \\
1787.996\end{array}$ & $a^{6} S-x^{6} P^{o}$ & $\begin{array}{l}6 \\
6 \\
6\end{array}$ & $\begin{array}{l}8 \\
6 \\
4\end{array}$ & $\begin{array}{l}23317.6 \\
23317.6 \\
23317.6\end{array}$ & $\begin{array}{l}0.743 \\
0.619 \\
0.444\end{array}$ \\
\hline $\begin{array}{l}4667 \ldots \ldots \ldots \ldots \ldots \\
4689 \ldots \ldots \ldots \ldots \ldots\end{array}$ & $\begin{array}{l}1808.2 \\
1816.7\end{array}$ & Si II & 1 & $\begin{array}{l}1808.012 \\
1816.928 \\
1817.451\end{array}$ & $3 p^{2} P^{o}-3 p^{2}{ }^{2} D$ & $\begin{array}{l}2 \\
4 \\
4\end{array}$ & $\begin{array}{l}4 \\
6 \\
4\end{array}$ & $\begin{array}{c}0 \\
287.3 \\
287.5\end{array}$ & $\begin{array}{l}-2.13 \\
-1.88 \\
-2.83\end{array}$ \\
\hline $\begin{array}{l}4885 \ldots \ldots \ldots \ldots \\
4930 \ldots \ldots \ldots \ldots \ldots \\
4961 \ldots \ldots \ldots \ldots \ldots\end{array}$ & $\begin{array}{l}1892.7 \\
1910.1 \\
1922.1\end{array}$ & $\mathrm{Fe}$ III & 34 & $\begin{array}{l}1895.456 \\
1914.056 \\
1926.304\end{array}$ & $a{ }^{7} S-z{ }^{7} P^{o}$ & $\begin{array}{l}7 \\
7 \\
7\end{array}$ & $\begin{array}{l}9 \\
7 \\
5\end{array}$ & $\begin{array}{l}30088.8 \\
30088.8 \\
30088.8\end{array}$ & $\begin{array}{l}0.48 \\
0.36 \\
0.21\end{array}$ \\
\hline 6614. & 2562.6 & $\mathrm{Fe}$ II & 64 & $\begin{array}{l}2563.304 \\
2564.245 \\
2567.683 \\
2578.695 \\
2583.357 \\
2592.318 \\
2594.504 \\
2611.853\end{array}$ & $a^{4} D-z{ }^{4} P^{o}$ & $\begin{array}{l}8 \\
6 \\
4 \\
2 \\
4 \\
6 \\
6 \\
2 \\
4\end{array}$ & $\begin{array}{l}6 \\
4 \\
2 \\
2 \\
4 \\
6 \\
4 \\
6\end{array}$ & $\begin{array}{l}7955.3 \\
8391.9 \\
8680.5 \\
8846.8 \\
8680.5 \\
8391.9 \\
8846.8 \\
8680.5\end{array}$ & $\begin{array}{r}0.071 \\
-0.215 \\
-0.609 \\
-0.575 \\
-0.449 \\
-0.485 \\
-1.217 \\
-1.367\end{array}$ \\
\hline
\end{tabular}

${ }^{\text {a }}$ Rest wavelengths for $z=1.581$, the redshift of the Al in absorption.

reach zero intensity near their red edges. Such wide absorptions may not be uncommon; among the nine BAL QSOs studied by Hazard et al. (1984), $0856+172$ is a QSO like $0059-2735$ in which the C IV absorption extends over most of the range between the $\mathrm{C}$ IV and $\mathrm{Si}$ IV emission lines. We note that the shape of the $\mathrm{Si}$ IV and $\mathrm{C}$ IV absorption profiles is opposite to the strong P Cygni lines in the O5f star $\zeta$ Pup. As described by Morton (1976) the lines of C III, C IV, N III, N IV, and $\mathrm{O}$ VI formed in this stellar wind decrease gradually to zero flux on the short-wavelength side of the emission line and then rise steeply to a terminal velocity of about $-2660 \mathrm{~km} \mathrm{~s}^{-1}$.

4. The broad absorption lines of $\mathrm{C} \mathrm{II}, \mathrm{Mg}$ II, $\mathrm{Al}$ II, and $\mathrm{Al}$ III are saturated and at least the last three have very steep red edges. Only two other QSOs are known to have broad Mg II absorption, $1232+134$ (He et al. 1984) and $1700+518$ (Turnshek et al. 1985; Pettini and Boksenberg 1985; Wampler 1985), but the $\mathrm{Mg}$ II does not drop to zero flux in either case. Similarly we are aware of only three examples, $1011+091$ and $1413+117$ (Hazard et al. 1984) and $1232+134$ (He et al. 1984), with Al III absorption, and in none of these is it saturated. C II absorption also is rare. The higher resolution AAT spectrum of 1985 September 4 has shown the Al II $\lambda 1670.8$ also is saturated, though it is not as wide as $\mathrm{Al}$ III or $\mathrm{Mg}$ II. Such strong $\mathrm{Al}$ II absorption has not been found in any other QSO.

Wampler (1985) and Pettini and Boksenberg (1985) have suggested that the $\mathrm{Mg}$ II absorption trough in $1700+518$ does not reach zero because the absorbing cloud does not cover the whole continuum emission region or because there is residual flux in the trough due to unresolved $\mathrm{Fe}$ II emission, which appears to be strong in some BAL QSOs. However in $0059-2735$, the zero central intensity at $\mathrm{Mg}$ II implies that the absorbing region covers the entire continuum emission, and possibly the line emission too, as suggested by the apparent absorption of the blue side of the $\mathrm{Mg}$ II emission.

5. The $\mathrm{C}$ II, $\mathrm{Mg}$ II, $\mathrm{Al}$ II, and $\mathrm{Al}$ III absorption lines are significantly narrower than the C IV and Si IV troughs, but all have very steep red edges with essentially the same redshift. Thus the lower ionization material is confined to the lowest velocity region where the $\mathrm{C}$ IV and Si IV are saturated.

6. Fe II is present in two broad features whose red edges require absorption from fine structure levels excited to at least $0.12 \mathrm{eV}$. This is the first QSO with either broad or narrow lines to have absorption from such highly excited fine-structure levels. Excitation of $\mathrm{C}$ iI to $0.008 \mathrm{eV}$ and $\mathrm{Si}$ II to $0.036 \mathrm{eV}$ has been reported in a few QSOs such as 3C 191, 0237-233, $1157+014$, and 2126-158 (Williams et al. 1975; Boronson et al. 1978; Wright et al. 1979; Young et al. 1979), but nothing higher. The widths of the Fe II troughs arise primarily from the superposition of many multiplet components rather than a range of velocities. Broad $\mathrm{Fe}$ II absorption of either form is not known in any other QSO.

7. A narrower absorption feature occurs around $7081 \AA$ 
which is most easily accounted for by UV multiplets 62 and 63 of Fe II which have lower levels between 1.0 and $1.1 \mathrm{eV}$.

8. Several narrow absorption lines are present which can be identified with transitions of $\mathrm{N}$ I, Fe II, and Fe III from levels excited to $2.9,3.6$, and $3.7 \mathrm{eV}$ respectively. The most convincing of these is the UV34 triplet of Fe III where each of the three lines has been detected. The required excitation of $3.7 \mathrm{eV}$ is much higher than previously observed for QSO absorption, even a BAL QSO. The Fe III UV34 triplet has been identified among the narrow emission lines in the QSO 0335-336 by Hartig and Baldwin (1986), but the absorption in our spectrum was entirely unexpected.

\section{CONCLUDING REMARKS}

Although high-ionization absorption troughs are typical of extreme examples of the BAL QSOs and narrow emission lines have been noted in some cases, we have found other features of $0059-2735$ that set it apart from all other known objects of this class of QSO. Most notable of these are the extensive system of low-ionization absorptions and particularly the complex system of iron absorption lines. While other examples of low-ionization absorption systems are known, they appear to be relatively rare and in no other cases are the lines of $\mathbf{M g ~ I I}$, $\mathrm{Al}$ II, and $\mathrm{Al}$ III so strong. The most significant feature, however, is the very probable presence of $\mathrm{Fe}$ II and Fe III absorptions from lower levels with excitations between 1.1 and $3.7 \mathrm{eV}$. In recent years the importance of Fe II emission in the spectra of QSOs has been increasingly emphasized, but blending of the multiple broad lines makes it extremely difficult to disentangle the various components. The shapes of the Fe II absorption troughs in $0059-2735$ indicate that the individual lines are very narrow and that high-resolution observations ought to separate the individual lines and multiplets and allow the determination of temperatures and densities in the $\mathrm{Fe}^{+}$clouds.

Detailed studies of $0059-2735$ could set severe constraints on models of BAL QSOs. The scarcity of this type of QSO may be an indication that the outflow of material is in the form of a jet rather than a disk type structure. The alignment of a very narrow jet toward the observer may also help explain strong $\mathrm{Fe}$ II absorption accompanied by weak Fe II emission.

On a practical level the discovery of $0059-2735$ shows the need to continue surveys that provide the rare examples which can yield vital clues to unraveling the nature of QSOs. It demonstrates the particular value of an objective prism in selecting interesting objects. The QSO 0059-2735 was not found by accident in a more or less random search of QSO spectra or even a survey of the rarer BAL QSOs. It was selected directly from the prism plate as having strong $\mathrm{Al} \mathrm{II} \mathrm{and} \mathrm{Al}$ III absorption and at a redshift which differed by only 0.02 from that later measured by slit spectroscopy. It was therefore known to be a highly unusual object before the observations with the AAT. The ability of such objective prism surveys to locate objects worthy of more detailed study ensures the optimum use of the larger telescopes and argues for the continued support of Schmidt facilities.

We thank the UK Schmidt Telescope Unit for the continuing supply of high-quality plate material without which these studies would not be possible, and the UK Panel for the Allocation of Telescope Time for the opportunity to follow up the discovery with the Anglo-Australian Telescope. We also are grateful to Raylee Stathakis of the Anglo-Australian Observatory for assistance in reducing the AAT data.

\section{REFERENCES}

Boronson, T., Sargent, W. L. W., Boksenberg, A., and Carswell, K. F. 1978, Ap. J., 220, 772 .

Boyle, B. J., Fong, R., Shanks, T., and Clowes, R. G. 1985, M.N.R.A.S., 216,

Morton, D. C. 1976, Ap. J., 203, 386.

. 1978, Ap.J., 222, 863

Morton, D.C., and Smith, W. H. 1973, Ap. J. Suppl., 26, 383

623 .

Campusano, L. E., and Torres, C. 1983, A.J., 88, 1304.

Clowes, R. G., and Savage, A. 1983, M.N.R.A.S., 216, 623.

Hartig, G. F., and Baldwin, J. A. 1986, Ap. J., 302, 64.

Hazard, C., and McMahon, R. G. 1988, Ap. J. Suppl., in preparation.

Hazard, C., Morton, D. C., Terlevich, R., and McMahon, R. G. 1984, Ap. J., 282, 33.

He, X-T., Cannon, R. D., Peacock, J. A., Smith, M. G., and Oke, J. B. 1984 M.N.R.A.S., 211, 443

Hewett, P. C., Irwin, M. J., Bunclark, P. Bridgeland, M. T., Kibblewhite, E. J.,

He, X. T., and Smith, M. G. 1985, M.N.R.A.S., 213, 971.

Johansson, S. 1978, Phys. Scripta, 18, 217.

Junkkarinen, V. T. 1983, $A$ p. J., 265, 73.

Kelly, R. L. 1979, NASA Technical Memorandum 80268

Kelly, R. L. and Palumbo, L. J. 1973, Naval Research Lab. Rept., 7599.

Kibblewhite, E. J., Bridgeland, M. T., Bunclark, P., and Irwin, M. J. 1984, in

Proc. Astronomical Microdensitometry Conf., ed. D. A. Klinglesmith (NASA

Conf. Pub. 2317), p. 277.

Kurucz, R. L., 1981, Smithsonian Ap. Obs. Spec. Rept., 390.

Kurucz, R. L., and Peytremann, E. 1975, Smithsonian Ap. Obs. Spec. Rept., 362.

Nandy, K., Reddish, V. C., Tritton, K. P., Cooke, J. A., and Emerson, D. 1977, M.N.R.A.S., 178, 63P.

Pettini, M., and Bokensberg, A. 1985, Ap. J. (Letters), 294, L73.

Selvelli, P. L., and Hack, M. 1985, Astr. Express, 1, 115

Turnshek, D. A., Foltz, C. B., Weymann, R. J., Lupie, D. L., McMahon, R. G., and Peterson, B. M. 1985, Ap. J. (Letters), 294, L1.

Turnshek, D. A., Weymann, R. J., Leibert, J. W., Williams, R. E., and Strittmatter, P. A. $1980, A$. J. $238,488$.

Wampler, E. J. 1985, Ap. J., 296, 416.

Weymann, R. J., and Foltz, C. B. 1983, in Quasars and Gravitational Lenses, (Liège: Université de Liège, Institut d'Astrophysique), p. 538.

Williams, R. E., Strittmatter, P. A., Carswell, R. F., and Craine, E. R. 1975, Ap. J., 202, 296.

Wills, B. J., Netzer, H., and Wills, D. 1980, Ap. J. (Letters), 242, L7.

Wills, B. 1985, Ap. J., 288, 94.

Wright, A. E., Morton, D. C., Peterson, B. A., and Jauncey, D. L. 1979 , M.N.R.A.S., 189, 611 .

Young, P. J., Sargent, W. L. W., Boksenberg, A., Carswell, R. F., and Whalen, J. A. J. 1979, Ap. J., 229, 891.

C. HAZARD: Department of Physics and Astronomy, University of Pittsburgh, Pittsburgh, PA 15260

RICHARD MCMAHON: Institute of Astronomy, University of Cambridge, Madingley Road, Cambridge CB3 0HA, U.K.

Donald C. Morton: Herzberg Institute of Astrophysics, National Research Council, Ottawa, Ontario, Canada, K1A OR6

JoHn K. WebB: Sterrewacht, Postbus 9513, 2300 RA, Leiden, The Netherlands 


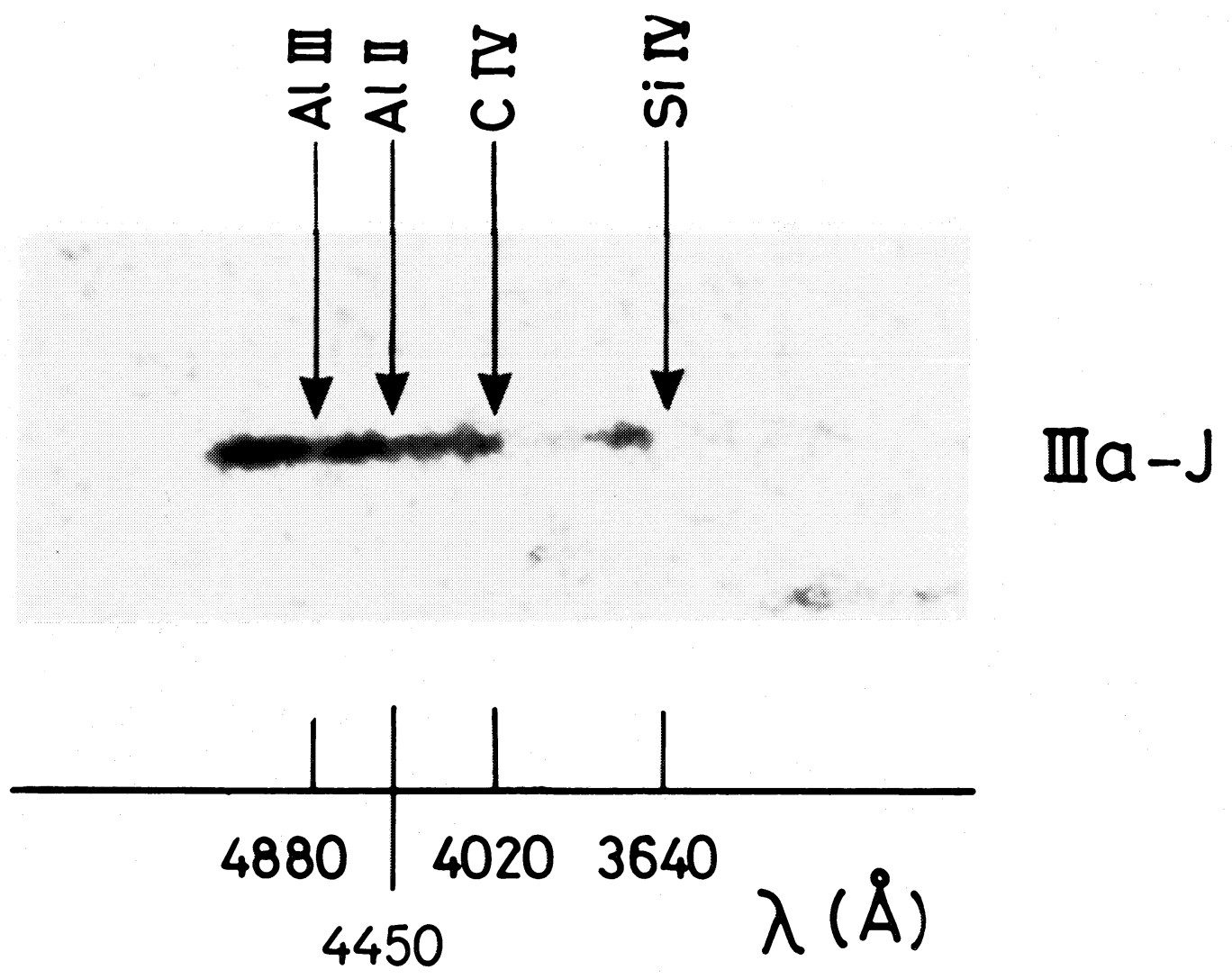

FIG. 1. - The IIIa-J objective-prism spectrum of 0059-2735 showing the features by which it was selected for further study. The spectrum is oriented with blue to the right. Reproduced by courtesy of the UK Schmidt Telescope Unit.

Hazard, MCMahon, WebB, and Morton (see 322, 263) 